\title{
Design na Leitura e multimodalidade: complexidade gráfica na formação visual do leitor
}

\author{
Design in Reading and multimodality: graphic complexity in readers' \\ visual education
}

Maíra Gonçalves Lacerda; Jackeline Lima Farbiarz

Design de livros, Design na Leitura, formação visual, políticas públicas de leitura, multimodalidade

Construir sentido para imagens é tarefa premente na contemporaneidade, imersa na multimodalidade. Mas será que formamos crianças e jovens para isso? Compreendendo que livros de literatura destinado a esse público, na grande maioria, encontram na relação verbo-visual seu espaço de fruição, a pesquisa debruçou-se sobre as questões: (1) qual a participação do Design, presente nos livros de literatura para crianças e jovens chancelados pelas políticas públicas, para a formação visual do leitor?; (2) existe uma progressão de complexidade gráfica desses objetos, correspondente ao desenvolvimento escolar do leitor? Propõe-se, por meio de análise gráfica dos livros selecionados pelo Programa Nacional Biblioteca da Escola, a organização de panorama relacionando aspectos gráficos e desenvolvimento escolar do leitor na Educação Infantil, Ensino Fundamental e Ensino Médio. Nesse processo, foi possível perceber que os acervos não apresentam em seu conjunto uma progressão, ao contrário, conforme os leitores avançam no processo escolar e na compreensão do conteúdo textual, conteúdo gráfico e imagético tendem a diminuir em quantidade e simplificar-se. Acreditando na formação de sujeitos leitores potentes na significação crítica da verbo-visualidade, para que se tornem agentes de mudanças dos sistemas ideológicos sociais que os circundam, propõe-se o Design na Leitura como um projeto político multimodal.

Book design, Design in Reading, visual education, public policies to promote reading, multimodality

Build meanings from images is a paramount task in contemporaneity, immersed in multimodality. Nonetheless, are we educating children and young people to do that? Acknowledging that most literature books for such audience find a conducive environment for fruition in the verbal-visual relationship, this research investigates: (1) what is the role of Design, present in the books for children and young people that are sealed by public policies, for these reader's visual education?; (2) Is there a progression of graphic complexity of such books that corresponds to the reader's school development? We conducted a graphic analysis of books and organized an overview relating graphic aspects to reader's school development in pre-, elementary, middle and high school. In this process, we perceived that they did not present a progression of visual complexity. On the contrary, as young readers advanced on their schooling and understanding of textual content, graphic and image content tended to reduce in number and to become simpler. Thus, this research proposes Design in Reading as a multimodal political project. This would enable children and young people to become empowered readers in verbal-visual meaning-making and reach the condition of transformation agents in the social systems that surround them.

Anais do $10^{\circ} \mathrm{CIDI}$ e $10^{\circ} \mathrm{CONGIC}$

Kelli C.A.S. Smythe, Rafael de Castro Andrade (orgs.)

Sociedade Brasileira de Design da Informação - SBDI

Curitiba | Brasil | 2021
Proceedings of the $10^{\text {th }} \mathrm{CIDI}$ and $10^{\text {th }}$ CONGIC

Kelli C.A.S. Smythe, Rafael de Castro Andrade (orgs.)

Sociedade Brasileira de Design da Informação - SBDI Curitiba | Brazil | 2021 


\section{Introdução: problema, método e abordagem}

O livro de literatura para crianças e jovens se caracteriza como objeto diferenciado dentro do mercado editorial por se constituir por meio da verbo-visualidade (Brait, 2013), isto é, de enunciados compostos pela junção das linguagens verbais - texto literário - e visuais ilustrações e projeto gráfico -, o que reforça a perspectiva do livro enquanto objeto multimodal de produção coletiva. Segundo Peter Hunt (2010, p. 43), para quem o livro para crianças está no "auge da vanguarda da relação palavra e imagem", grande parte da complexidade narrativa desses objetos se encontra nos elementos visuais, que - apesar do alcance universal e da identificação com o público ainda em processo de formação e alfabetização - não exigem menos do ato de ler. Mas será que estamos formando crianças e jovens capacitadas a construir sentidos para enunciados verbo-visuais?

Ao pensarmos os livros de literatura para crianças e jovens dentro do contexto educacional, percebemos que, em termos do conteúdo textual, existem, nos campos da Literatura e da Educação, critérios que possibilitam a avaliação e seriação das obras de acordo com faixa etária e nível de ensino, estimulando o aprendizado do leitor e o progresso da sua inserção na cultura letrada. Apesar de acreditarmos que tais critérios não atendem às especificidades do sujeito, compreendemos que tal organização é necessária dentro da lógica de funcionamento da instituição escolar. Ao pensarmos, contudo, no conteúdo gráfico e imagético de tais objetos, não encontramos critérios claros de avaliação ou análise de sua adequação às diferentes etapas escolares, nem identificamos, no projeto gráfico e de ilustração dos próprios objetoslivro, a intenção de uma progressão de complexidade com vistas a uma formação visual do leitor. Quando falamos em progressão de complexidade, falamos de um desenvolvimento dos múltiplos aspectos que compõem o livro de forma a torná-lo continuamente mais complexo e propiciador de mais camadas significativas para a leitura.

É de fundamental importância para um sujeito vivendo na sociedade contemporânea e em contato constante com a multimodalidade, na qual diversos sistemas comunicacionais interagem e se relacionam, produzir e interpretar significados a partir das imagens que $o$ circundam. Partindo desse raciocínio, conceituamos formação visual como o processo de educação do olhar e de significação das imagens e das representações gráficas pelo sujeito, a partir da compreensão desses recursos enquanto partes formadoras de uma linguagem visual, um sistema de signos que contém significado.

O presente trabalho objetiva apresentar um panorama da progressão de complexidade gráfica dos livros de literatura para crianças e jovens, ao se debruçar sobre as seguintes questões: qual a participação do Design, presente nos livros de literatura para crianças e jovens chancelados pelas políticas públicas, para a formação visual do leitor? Existe uma progressão de complexidade gráfica de tais livros correspondente ao desenvolvimento escolar do leitor? Para tal, organizou-se o seguinte percurso metodológico: 
1. pesquisa bibliográfica de referencial teórico;

2. pesquisa documental sobre os Parâmetros Curriculares Nacionais - PCNs e os editais do Programa Nacional Biblioteca da Escola - PNBE;

3. mapeamento e aprimoramento de categorias de análise e categorização para análise gráfica dos livros selecionados pelo PNBE 2013 e 2014 para Educação Infantil, anos iniciais e finais do Ensino Fundamental e Ensino Médio;

4. organização de panorama a respeito da progressão de complexidade gráfica dos livros de literatura voltados para crianças e jovens chancelados pelas políticas públicas.

Em situação ideal, com vistas a um projeto de formação visual do sujeito, defendemos que a linguagem visual deveria acompanhar o movimento da linguagem verbal, isto é, crescer em complexidade conforme o leitor avança no seu processo de formação e ganha mais possibilidades para compreender e interpretar os diversos conteúdos. Ao avaliarmos essa progressão, todavia, precisamos considerar que nem sempre estamos lidando com critérios objetivos, já que nosso objeto de estudo é um objeto de arte, e a arte escapa muitas vezes em direção ao subjetivo e ao particular. Mas quando se pondera sobre o livro de literatura para crianças e jovens inserido no contexto escolar, e mais especificamente no conjunto desses objetos que formam o acervo disponível aos estudantes por meio de políticas públicas, é necessário que, salvaguardando seu valor literário e estético, ele esteja inserido em um pensamento pedagógico com vistas à formação do leitor, tanto em relação ao conteúdo textual quanto visual.

Apresentamos, então, o Design na Leitura como um projeto político multimodal, um projeto interdisciplinar com vistas à fruição do futuro leitor, pensado como ser social e dinâmico participante de um cenário de políticas públicas de leitura, visando ao seu diálogo com o objeto-livro e todas as pessoas participantes de sua produção (Lacerda et al., 2013, p. 166). Tal conceito oferece nova possibilidade metodológica para sustentação de análises no âmbito do Design da Informação ao ampliar o campo do Design do livro, para além de referir-se unicamente ao projeto do objeto-livro em si, levando-o a alcançar a concepção de um projeto para a mediação do ato de ler.

\section{Processo de pesquisa: uma metodologia de análise para a verbo-visualidade}

A literatura possibilita ao leitor, por meio da fruição estética, a reflexão a respeito da realidade, de si mesmo e do outro. Contudo, quando lidamos com a leitura literária para crianças e jovens, especialmente em ambiente escolar, é necessário que se tenha um olhar sensível para as fases de formação do sujeito, na consideração das mediações de leitura oferecidas para cada etapa educacional, que deve tratar do desenvolvimento físico, intelectual, emocional e social do sujeito, na especificidade da faixa etária a que atende, sem perder de vista o caráter contínuo do processo de escolarização. 
Uma das ferramentas utilizadas pelo governo brasileiro para garantir o acesso à literatura, reconhecida pelo Ministério da Educação como direito de todo indivíduo, foi o Programa Nacional Biblioteca da Escola - PNBE, desenvolvido de 1997 a 2014. Tendo o objetivo de avaliar, adquirir e distribuir obras literárias para formar a biblioteca escolar e promover a inserção na cultura letrada e na leitura literária de estudantes e professores de todo o ciclo básico - Educação Infantil, Ensino Fundamental e o Ensino Médio -, o PNBE atendia todas as escolas públicas municipais, estaduais e federais.

Buscando atender aos objetivos da pesquisa, foram definidos como objeto de análise os acervos de obras literárias selecionados pelo PNBE dos anos de 2013 e 2014, últimos anos de realização do programa, para Educação Infantil (creche e pré-escola), anos iniciais do Ensino Fundamental (do $1^{\circ}$ ao $5^{\circ}$ ano), anos finais do Ensino Fundamental ( $6^{\circ}$ ao $9^{\circ}$ ano) e Ensino Médio. As opções metodológicas adotadas utilizam técnicas pertencentes à metodologia de análise do conteúdo (Bardin, 2009), e englobam o mapeamento e a organização de categorias para análises quantitativa e qualitativa. A partir da "regra da representatividade" (Ibid., p. 123), definiu-se uma amostragem para delimitação do corpus, estipulando para análise $25 \%$ de todos os livros selecionados para cada etapa escolar. Foram então instituídas tipologias, capazes de categorizar essas relações, para o desenvolvimento da análise quantitativa e posterior inferência qualitativa.

\section{Tipologia 1: Classificação da materialidade e do conteúdo verbo-visual}

Derivada das organizações realizadas por Sophie Van der Linden (2011, pp. 24-26) e por Maria Nikolajeva e Carole Scott (2011, p. 21), ao considerarmos a realidade editorial brasileira e os objetos-livro inclusos no edital do PNBE:

- Livro sem ilustração: composto somente por texto.

- Livro com vinhetas: apresenta texto acompanhado de vinhetas ilustradas.

- Livro com ilustração: apresenta texto acompanhado de ilustrações, sendo que o texto é espacialmente predominante e autônomo do ponto de vista do sentido.

- Livro ilustrado: a narrativa se faz de maneira articulada entre texto e imagens.

- Livro de imagem: narrativa composta somente por imagem.

- História em quadrinho: articula imagens sequenciais organizadas em disposição compartimentada.

\section{Tipologia 2: Classificação da presença de diferencial gráfico}

Apresenta as possibilidades de diferencial gráfico nos livros para crianças e jovens,

organizadas a partir da Paleta do designer de livros de Haslam (2007, p. 30) e dos conceitos de Camargo (1995), ampliadas e reorganizadas. A classificação nessas categorias é realizada de acordo com a percepção, muitas vezes subjetiva, da ênfase dada pelo projeto do livro ao componente do Design em questão. Contudo, é importante informar que não se pretende aplicar as presentes categorias a partir de uma perspectiva de valor - positivo ou negativo - 
mas apenas para possibilitar um olhar a respeito da participação dos elementos no Design no projeto dos livros selecionados. Suas categorias são:

- Soluções diferenciadas no suporte.

- Soluções diferenciadas na malha gráfica.

- Soluções tipográficas diferenciadas.

- Soluções cromáticas diferenciadas.

- Soluções diferenciadas no acabamento.

- Nenhuma solução diferenciada.

\section{Tipologia 3: Classificação da relações entre texto e imagem nos aspectos narrativos}

Trata da relação que se estabelece entre texto e imagem na construção da narrativa verbovisual, a partir dos vínculos organizados por Linden (Ibid., pp. 120-121):

- Relação de redundância: as duas linguagens - texto e imagem - remetem à mesma narrativa e não produzem nenhum sentido suplementar, podendo ser compostas em sobreposição total ou parcial dos conteúdos.

- Relação de colaboração: texto e imagem trabalham em conjunto, em vista de um sentido comum, e constroem, de forma articulada, um discurso único que emerge da colaboração entre os dois.

- Relação de disjunção: texto e imagem não entram em estrita contradição, mas não se detecta nenhum ponto de convergência entre as linguagens, que podem apresentar histórias ou narrações paralelas.

\section{Livros em observação: panorama de progressão de complexidade gráfica}

A partir dessas categorias foram realizadas análises do corpus, que possibilitaram a visualização de certos movimentos dos objetos-livro quando relacionados ao desenvolvimento do estudante nas diferentes etapas escolares, especialmente em relação à materialidade e à linguagem visual. Em termos do conteúdo verbal, o movimento de crescimento da complexidade é claro e condizente com o progresso escolar do leitor. Contudo, quando avaliamos o conteúdo visual do acervo, essa dinâmica não se mostra tão perceptível. Dessa forma, buscamos a organização de um panorama para compreender esses movimentos.

Quanto à materialidade, percebemos que, conforme o estudante avança pelas etapas escolares, ele é apresentado a uma maior variedade de objetos-livro. Contudo, essa variedade, de fato, significa que os acervos passam a englobar objetos-livro cuja linguagem verbal tem primazia sobre a linguagem visual, e, exceto pela entrada dos livros de história em quadrinho em pequenas proporções, verifica-se a simplificação gráfica desses objetos. O livro ilustrado, maioria absoluta nos acervos destinados à Educação Infantil e aos anos iniciais do Ensino Fundamental, que demanda a articulação entre as linguagens verbal e visual pelo leitor durante a experiência de leitura, perde espaço progressivamente até sua ausência no acervo destinado 
ao Ensino Médio. Em movimento contrário, o livro sem ilustração, categorização com menor complexidade gráfica, parte da inexistência nos primeiros acervos para a superioridade absoluta ao final da Educação Básica.

Figura 1: Gráfico com análise quantitativa da Tipologia 1 - Classificação da materialidade e do conteúdo verbo-visual.

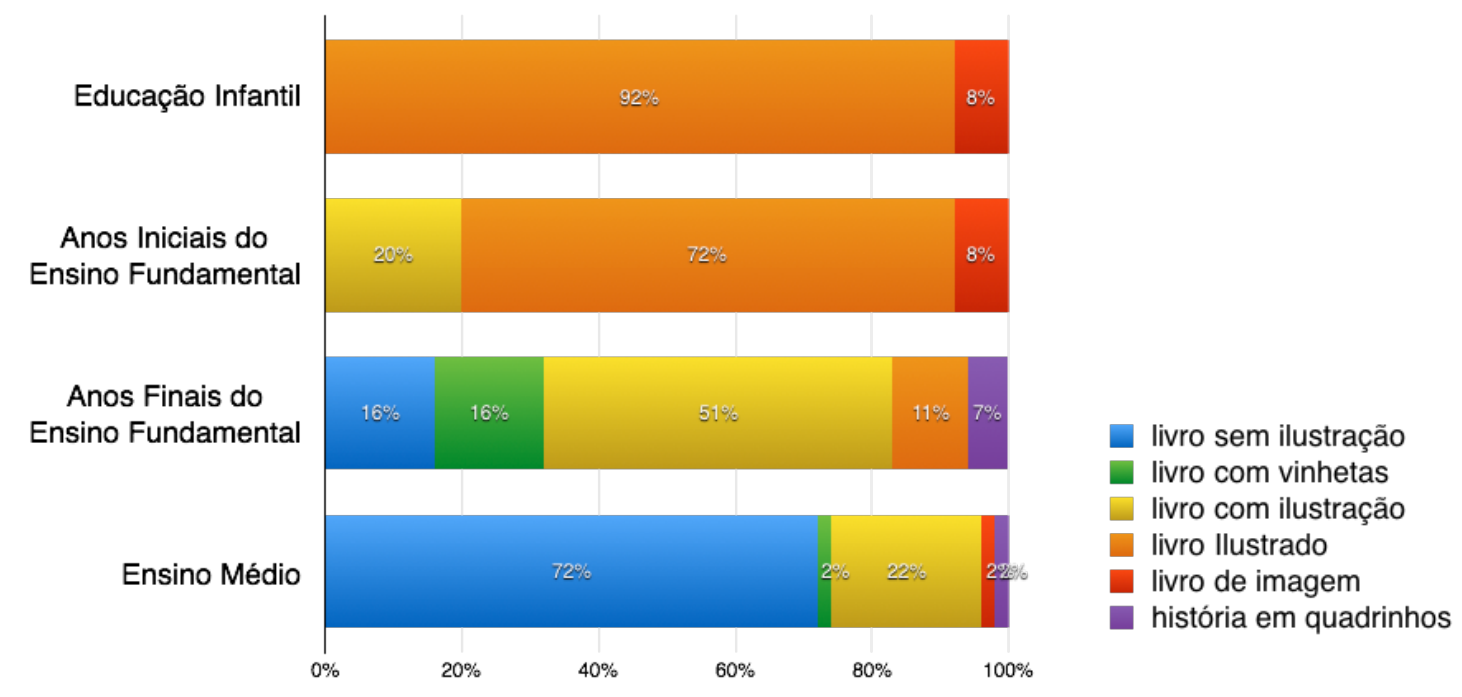

Para exemplificar essa movimentação, organizou-se o painel a seguir, composto por objetos-livro de cada acervo nas categorizações predominantes. Buscando manter um paralelismo comparativo, foram selecionadas obras de dois escritores renomados e premiados, sendo os mesmos também responsáveis pelas ilustrações, quando presentes. Por esse painel, composto, respectivamente, por Tom (Neves, 2012), Bichos do lixo (Gullar, 2013), Maroca \& Deolindo e outros personagens em festas (Neves, 2011) e Poemas escolhidos (Gullar, 2012), obras de qualidade inquestionável e adequadas ao público-alvo a que se destinam, é possível perceber a brusca ruptura do conteúdo visual no objeto-livro destinado ao estudante do Ensino Médio. 
Figura 2: Painel comparativo da Tipologia 1 - Classificação da materialidade e do conteúdo verbo-visual.

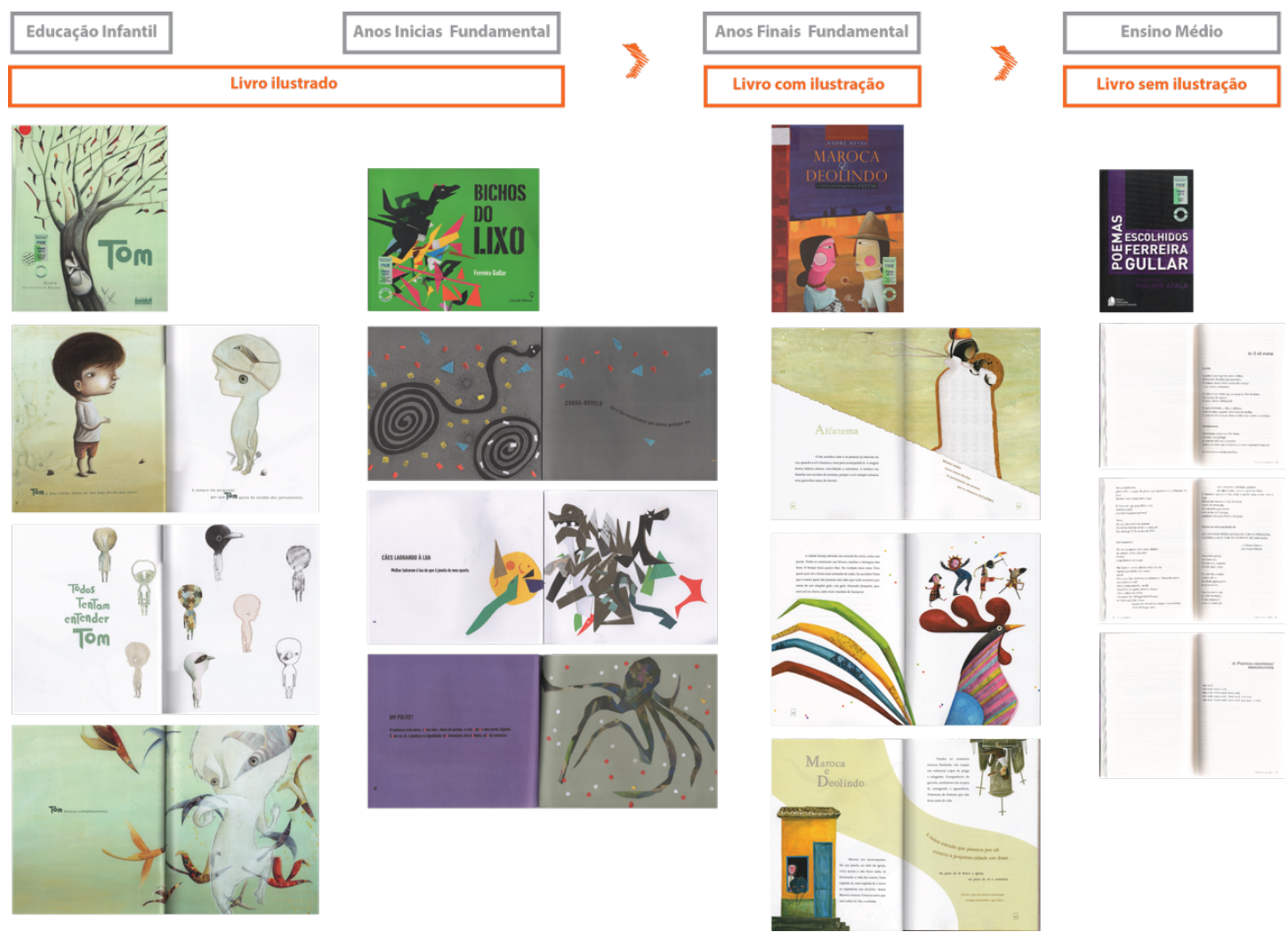

Cabe ressaltar que não se defende que todos os livros devam ser livros ilustrados ou mesmo livros com ilustração, e nem se critica diretamente as escolhas editoriais do livro Poemas escolhidos (Gullar, 2012), apresentado no painel como exemplificação. A questão em debate é que a grande maioria dos livros destinados ao Ensino Médio não apenas não possui qualquer tipo de ilustração como também não apresenta recursos gráficos capazes de compor uma linguagem visual elaborada. Dessa forma, ao olharmos para o conjunto do acervo ofertado aos jovens estudantes, percebemos um "silêncio" da linguagem visual, que se apresenta de forma neutra nos diferentes livros e limita o diálogo potencial com o sujeito leitor, afastando os objetos do conceito de Design na Leitura.

A ríspida suspensão da participação ativa da linguagem visual na construção do objeto-livro quebra uma expectativa do leitor em relação ao objeto, construída desde a Educação Infantil, na qual o livro é visto como objeto multimodal, e o afasta do contato com a imagem e com os recursos gráficos conectados à construção de significados, dessa forma interrompendo qualquer possibilidade de um processo de formação visual do estudante.

$\mathrm{Na}$ análise do diferencial gráfico os dados ratificam tal afirmação, indicando um aumento progressivo de objetos-livro sem nenhum diferencial, demonstrando a queda constante da diversidade gráfica apresentada ao leitor durante seu desenvolvimento escolar. Enquanto uma grande maioria dos acervos destinados às crianças investe em elementos estruturais e do design gráfico diversificados, que possibilitam a singularidade do objeto-livro, aqueles destinados aos jovens apresentam progressivamente menos diferencial e cada vez mais caraterísticas padronizadas, neutras e sem distinção. 
Figura 3: Gráfico com análise quantitativa da Tipologia 2 - Classificação da presença de diferencial gráfico (valores absolutos).

\section{Educação Infantil}

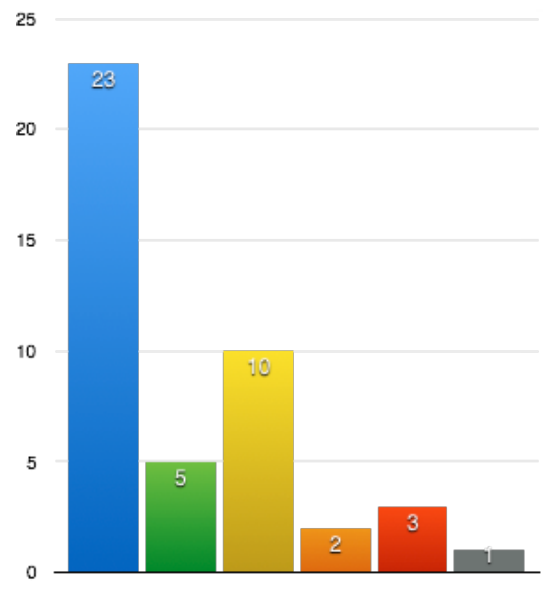

Anos Iniciais do Ensino Fundamental

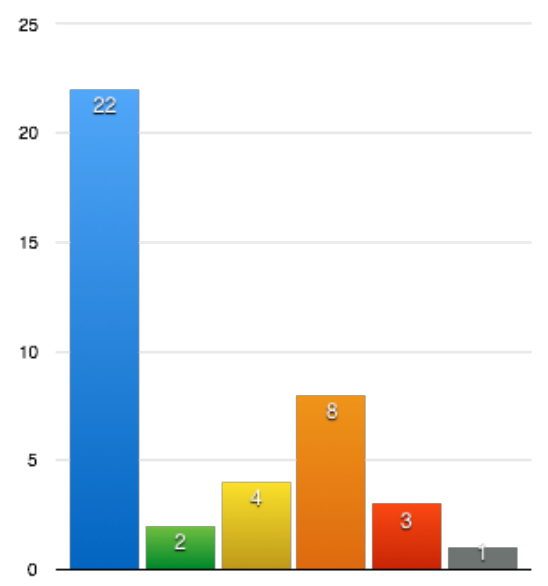

\section{Anos Finais do Ensino Fundamental Ensino Médio}
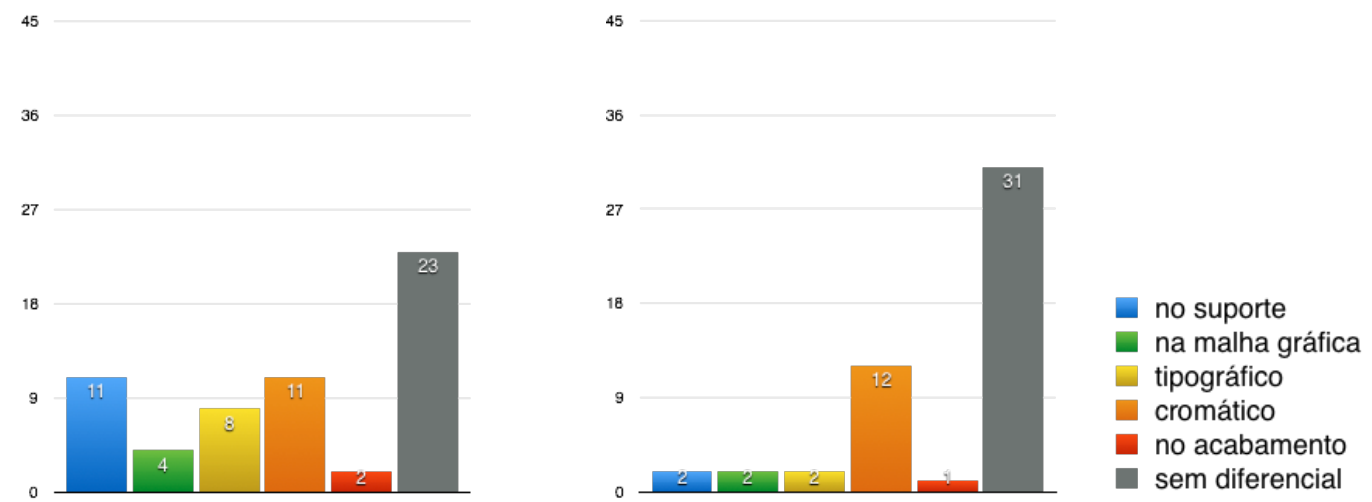

Considerando que, quando atrelados a um projeto condizente com o conceito de Design na Leitura, a variedade de diferencial gráfico possibilita que a linguagem visual participe da experiência de leitura e atue como mediadora, podemos afirmar que essa mesma variedade possibilita ao leitor maior contato com representações imagéticas e gráficas, aumentando seu repertório e participando ativamente da sua formação visual. Portanto, organizamos os dados da presença de diferencial gráfico de forma a identificar o quantitativo de soluções diferenciadas por objeto-livro, e percebemos que apesar dos valores numéricos decrescerem conforme se avança nas etapas escolares, existe uma resistência que mantém a diversidade mesmo no acervo destinado ao Ensino Médio. 
Figura 4: Gráfico com análise quantitativa da Tipologia 2 - Classificação da presença de diferencial gráfico.

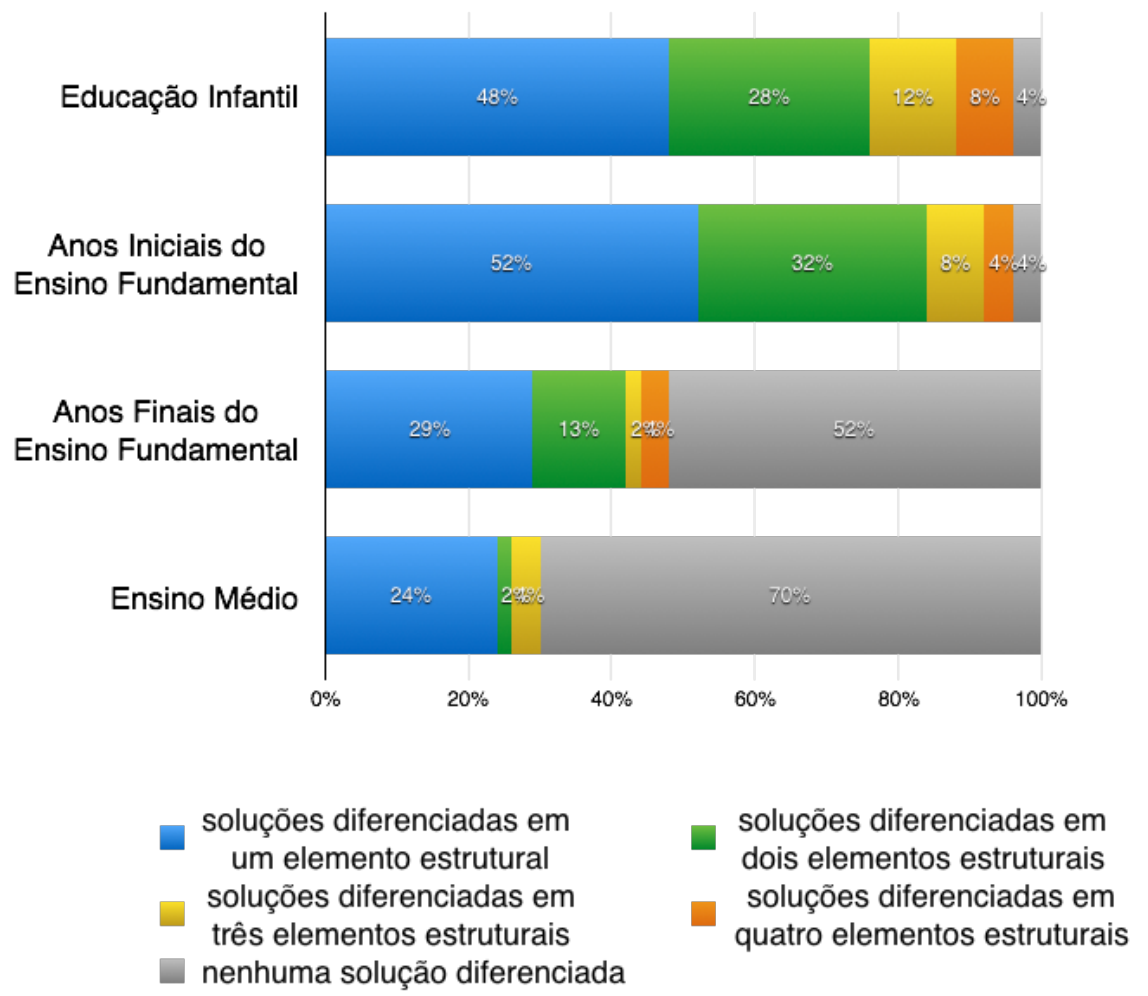

Buscando exemplificar como a variedade de diferencial gráfico pode participar da construção de significados durante a experiência de leitura e contribuir para formação visual do leitor, apresentamos o painel a seguir com os objetos-livro possuidores da maior quantidade de diferencial por acervo. Em todos os casos, elementos estruturais do objetolivro são utilizados em soluções diferenciadas que os aproximam do conceito de Design na Leitura ao potencializar o diálogo entre as diferentes linguagens que compõem o objeto-livro e os sujeitos leitores a quem se destinam. No livro ilustrado Alô, mamãe!; Alô, papai! (Horn, 2013), ao apresentar duas capas e dois inícios, o suporte possibilita ao leitor a escolha entre as duas narrativas do livro, dependendo do manuseio do objeto. Os dois diálogos telefônicos, entre a menina e sua mãe e o menino e seu pai, ambos questionando sobre o retorno do adulto a casa, são permeados pela imaginação e pela fantasia, com malha gráfica, tipografia e paleta cromática colaborando para a mediação da leitura. No projeto gráfico de Mayumi Okuyama para o livro ilustrado Bichos do lixo (Gullar, 2013), suporte, malha gráfica, tipografia e paleta cromática trabalham de forma diferenciada para acompanhar os poemas e as ilustrações do autor, dando plasticidade ao texto, à imagem e ao objeto-livro. No livro com ilustrações Maroca \& Deolindo e outros personagens em festas (Neves, 2011), diferentes contos inspirados nas festividades da tradição popular são apresentados por meio de suporte, malha gráfica, tipografia e cores diferenciadas, capazes de representar a vivacidade e a riqueza da cultura brasileira. E, por último, no livro com ilustrações Longas cartas para ninguém (Braz, 2011), o projeto gráfico realizado pelo Estúdio Versalete - Ana Sofia Mariz e Christiane Mello - possibilita que tipografia, cor e acabamento trabalhem de forma conjunta 
para que o leitor adentre a experiência árdua do jovem personagem ao se deparar com questões sobre a vida e a morte.

Figura 5: Painel comparativo da Tipologia 2 - Classificação da presença de diferencial gráfico.

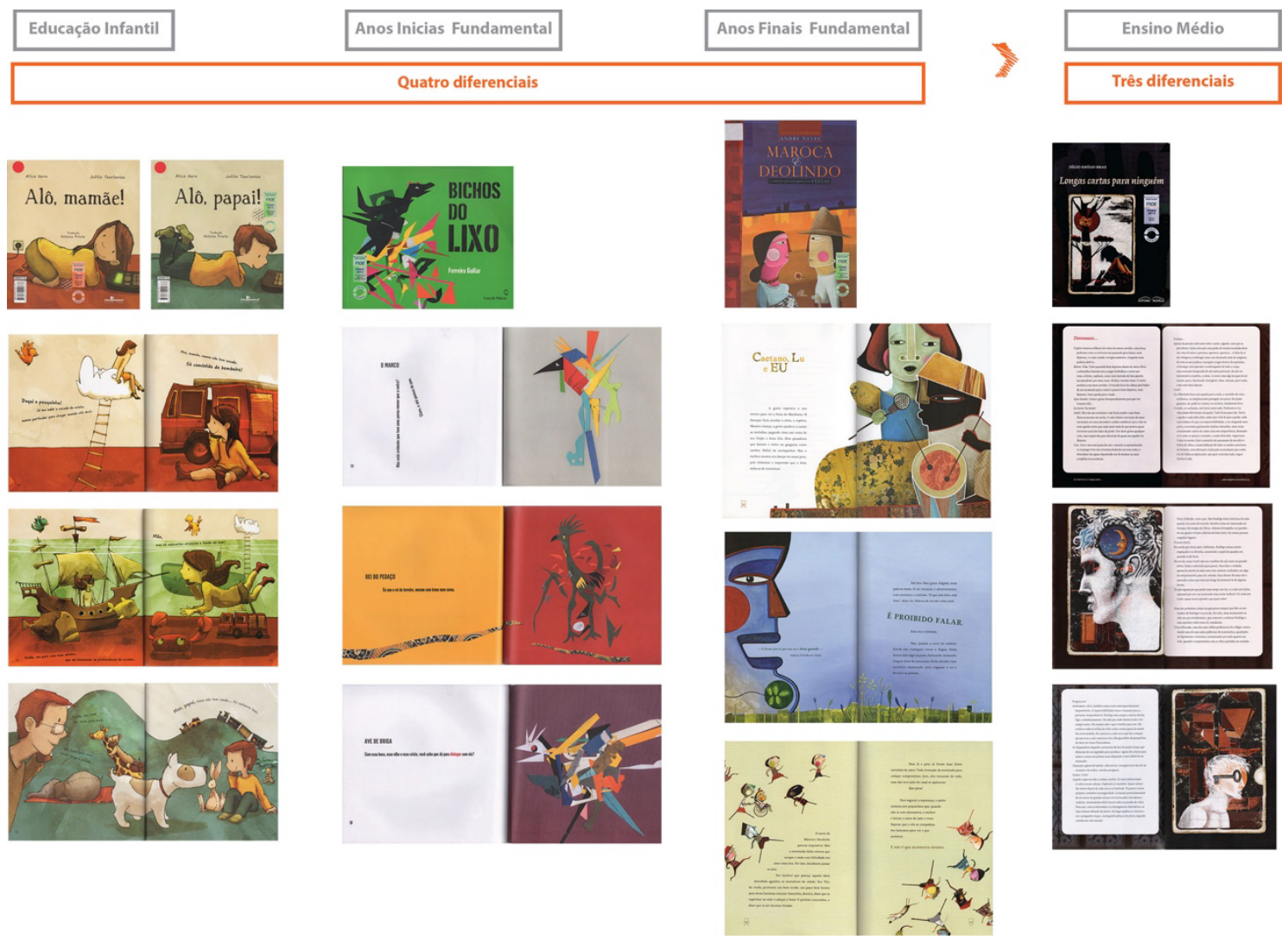

Ao analisarmos as relações entre texto e imagem, percebemos que as narrativas se constroem majoritariamente em redundância em todos os acervos. Com conteúdo textual e conteúdo imagético se repetindo sempre, mesmo após a completa alfabetização do estudante, é justificado o senso comum que subordina a ilustração ao texto e a considera algo descartável quando o sujeito passa da infância à juventude, fato identificável no aumento constante da porcentagem de livros sem ilustração, identificados nessa categorização como "não se aplica". Se a imagem não produz novos significados e não participa ativamente da construção narrativa, seu potencial enquanto linguagem não é explorado pelo projeto editorial e, portanto, não é identificado pelo leitor, que passa a corroborar e participar do senso comum. As ilustrações, que na infância ajudam o leitor a percorrer o objeto-livro e desvendar seu conteúdo literário, passam a uma reprodução que, apesar de fornecer conceitos estéticos, não dialogam no seu potencial significativo com o leitor.

A relação de colaboração, que possibilita ao leitor compreender as ilustrações como parte constituinte da narrativa, capaz de agregar informação e contribuir com o conteúdo textual, segue em segundo lugar na categorização por quase todos os acervos, igualando-se com a redundância no Ensino Médio. Tal empate, apesar de se realizar com um valor percentual bastante baixo, demonstra certa preocupação positiva do mercado editorial com a função da 
ilustração nos livros destinados ao jovem estudante. Todavia a disjunção, que propicia diferentes narrativas nos diferentes conteúdos e solicita que o leitor busque relacioná-las por meio da experiência de leitura, possui uma participação pequena nas primeiras etapas escolares, mas não é considerada uma possibilidade para o Ensino Médio, onde seria mais importante, considerando-se um projeto de formação visual.

Figura 6: Gráfico com análise quantitativa da Tipologia 3 - Classificação da relações entre texto e imagem nos aspectos narrativos.

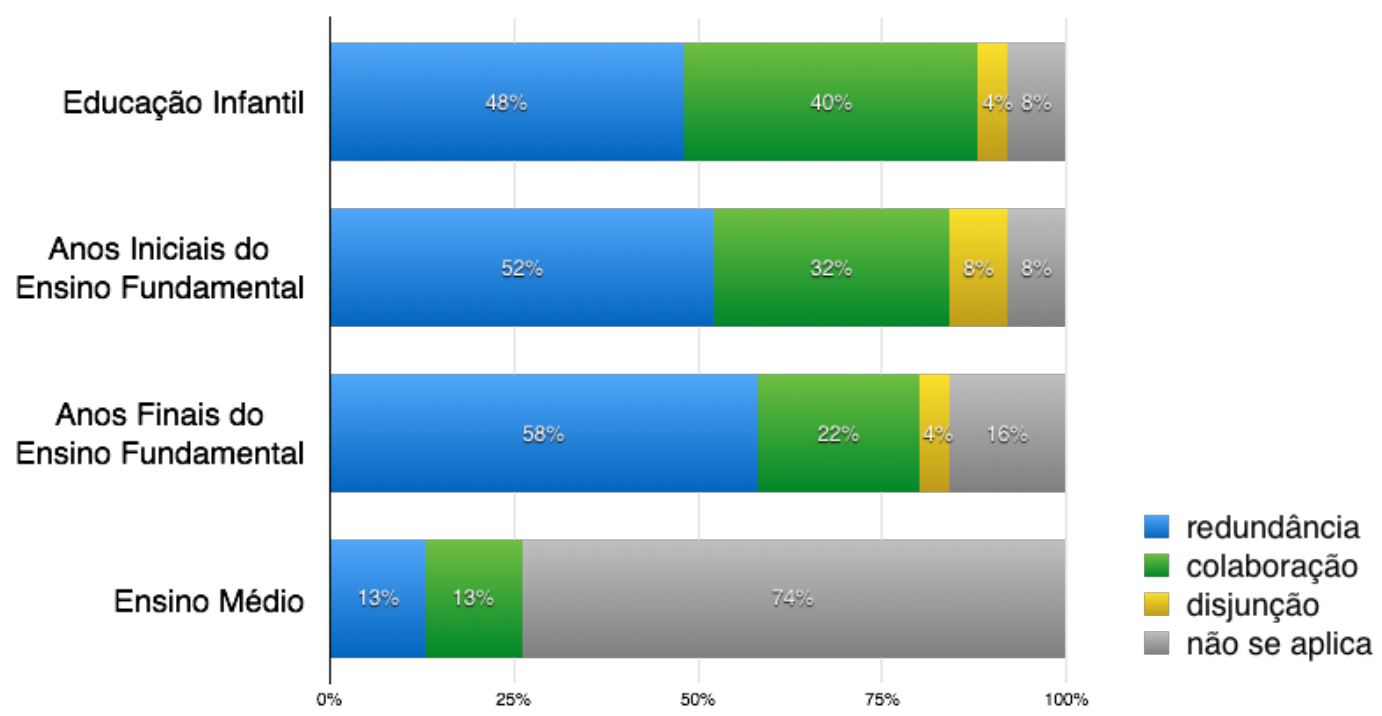

Vale ressaltar que defendemos que cada objeto-livro deve ser concebido de acordo com um projeto, capaz de unir representação gráfica e conteúdo textual de forma interdisciplinar em prol da narrativa e do diálogo com seu leitor potencial por meio do Design na Leitura, e, portanto, cada objeto-livro deverá ter soluções únicas e singulares a partir dos contextos de sua produção editorial. Contudo, argumenta-se que a complexidade gráfica do acervo, assim como a complexidade do conteúdo verbal, deveria crescer conforme o estudante avança nas etapas escolares, o que não é verificado de forma constante pelas análises e pelo panorama apresentado. Ao inverso, com algumas exceções, o que percebemos é um decréscimo de complexidade conforme se passa para o Ensino Fundamental e o Ensino Médio, encerrando uma possibilidade formativa e segregando a linguagem visual como algo que só caberia à Educação Infantil.

Segundo a escritora, professora e pesquisadora Nilma Lacerda e o especialista em Literatura Infantil e Juvenil e ex-diretor de Livro, Leitura, Literatura e Bibliotecas do Ministério da Cultura, Volnei Canônica, no evento literário Roda de Prosa, realizado na Universidade Federal Fluminense (2017), o livro de literatura é o primeiro museu da criança, na medida em que permite o contato visual com ilustrações, muitas delas de projeto estético sofisticado, preparando a percepção infantil para a construção de significados a partir de uma iconografia nacional e universal. Ao reconhecermos o livro como suporte para a arte a partir da relação verbo-visual, ao alcance de crianças e jovens por meio da sua inserção nos espaços escolares, 
é possível reconhecê-lo como objeto participante da formação do sujeito para a multimodalidade. Ao observarmos os acervos analisados nesta pesquisa, todavia, concluímos que essa participação ocorre apenas nas etapas iniciais da Educação Básica, quando os objetos-livro apresentam uma linguagem visual ativa e maior complexidade gráfica.

Considerando que, enquanto ativo, o PNBE representava um recorte da melhor produção editorial para crianças e jovens, podemos inferir que os resultados obtidos nas análises e nos painéis refletem o pensamento geral a respeito do objeto-livro, incluindo autores, editores, professores, bibliotecários e, especialmente, leitores. A despeito de os Parâmetros Curriculares Nacionais, as Diretrizes Nacionais Gerais da Educação Básica e as políticas públicas de leitura, como o PNBE, reconhecerem a importância de uma formação multimodal do sujeito, que o capacite a agir criticamente na sociedade a partir de diferentes modos comunicacionais, os objetos-livro selecionados para viabilizar esse projeto não materializam tal conceito, uma vez que ao relacioná-los com o processo de formação do leitor e do sujeito percebemos um movimento que privilegia a linguagem verbal. A partir da pesquisa desenvolvida, podemos perceber que, apesar da grande participação da linguagem visual nos objetos-livro destinados aos primeiros anos escolares, não existe um projeto estético de formação visual do leitor que acompanhe o desenvolvimento do estudante, mas apenas um projeto pedagógico verbal e projetos individuais dos objetos-livro, que atendem a questões editoriais e de marketing.

\section{Resultados e conclusões: Design na Leitura como projeto político multimodal}

A partir da pesquisa, identificamos que o Design presente nos livros de literatura para crianças e jovens chancelados pelas políticas públicas participa da formação visual do leitor de forma distinta para as diferentes etapas escolares. Assim, conforme os leitores avançam no processo escolar e na compreensão do conteúdo verbal presente no objeto-livro, o conteúdo visual tende a diminuir em quantidade e complexidade. Enquanto na Educação Infantil e nos anos iniciais do Ensino Fundamental foram identificados acervos extremamente ricos no aspecto verbo-visual - com predominância do livro ilustrado (92\% e $72 \%$ dos acervos), variedade de relações entre texto e imagem nos aspectos narrativos e diversidade de diferencial gráfico (totalizando $96 \%$ dos dois acervos com algum diferencial) -, conforme avançamos para os anos finais do Ensino Fundamental e do Ensino Médio encontramos um cenário mais uniforme - com o avanço dos livros sem ilustração (alcançando $72 \%$ do acervo no Ensino Médio) e sem diferencial gráfico (totalizando 52\% e 70\% sem nenhum diferencial nos dois acervos, respectivamente).

Identificamos que o Design não apresenta uma progressão de complexidade gráfica correspondente ao desenvolvimento escolar do leitor, pois enquanto crianças da Educação Infantil e dos anos iniciais do Ensino Fundamental são estimuladas a construir sentidos por meio da verbo-visualidade, nos anos finais do Ensino Fundamental e, especialmente, no Ensino Médio o conteúdo verbal é privilegiado e os jovens encontram poucas possibilidades gráficas e visuais, 
com limitado repertório ao seu alcance. Contudo, alguns exemplos foram capazes de demonstrar a importância e potência da linguagem visual em todas as etapas escolares.

O livro de literatura possibilita a crianças e jovens o contato com a subjetividade, e possibilita que, por meio da experiência literária, o leitor encontre perspectivas diversificadas que o ajudam a projetar o futuro. Constata-se, portanto, a relevância do processo de formação do leitor, e defendemos que tão importante quanto a formação do sujeito para a cultura letrada é sua formação visual. Por meio dessa pesquisa, acreditamos estar contribuindo para evidenciar o potencial do Design em tal processo, fator que ganha especial relevância ao considerarmos o momento presente de questionamento e transformação de parâmetros para Educação no Brasil.

A partir da realidade atual, de um mercado editorial para crianças e jovens que cresceu e se sustentou por anos a partir das compras governamentais fomentadas pelas políticas públicas, que se encontram suspensas ou limitadas de forma extrema, e de uma sociedade com abismos sociais que inviabilizam o acesso e o direito ao livro, falas oficiais que identificam tal objeto, em sua potência verbo-visual, como sendo da ordem do luxo e mesmo do supérfluo (Neto, 2018), restringem a produção de sentidos, negam a multimodalidade e intensificam a exclusão social. Reafirmamos que a formação de crianças e jovens como sujeitos leitores potentes na interpretação e significação da verbo-visualidade, por meio do contato com livros possuidores de um projeto de Design na Leitura, possibilita que se tornem sujeitos críticos e agentes de mudanças dos sistemas ideológicos sociais circundantes.

\section{Agradecimento}

Agradecemos à Capes e à Vice-reitoria Comunitária da PUC-Rio pelos auxílios concedidos, que permitiram o pleno desenvolvimento da pesquisa de doutorado da qual este artigo é fruto.

\section{Referências}

Bakhtin, M. (2010). Marxismo e filosofia da linguagem: problemas fundamentais do método sociológico da linguagem. Tradução Michel Lahud e Yara Frateschi Vieira, colaboração de Lúcia Teixeira Wisnik e Carlos Henrique D. Chagas Cruz. 14ª ed. São Paulo: Hucitec.

Bardin, L. (2009). Análise de Conteúdo. Tradução Luís Antero Reto e Augusto Pinheiro. Edição Revista e Actualizada. Lisboa: Edições 70 Ltda.

Brait, B. (2013) Olhar e ler: verbo-visualidade em perspectiva dialógica. Bakhtiniana. Revista de Estudos do Discurso, v. 8 (2), pp. 43-66.

Brasil. (2011) Edital de Convocação 08/2011: Edital de Convocação para inscrição e seleção de obras de literatura para o Programa Nacional Biblioteca da Escola PNBE 2013. Brasília: Ministério da Educação; Fundo Nacional de Desenvolvimento da Educação; Secretaria de Educação continuada, alfabetização, diversidade e inclusão; Secretaria de Educação Básica.

Brasil. (2012) Edital de Convocação 04/2012: Edital de Convocação para inscrição e seleção de obras de literatura para o Programa Nacional Biblioteca da Escola PNBE 2014. Brasília: 
Ministério da Educação; Fundo Nacional de Desenvolvimento da Educação; Secretaria de Educação continuada, alfabetização, diversidade e inclusão; Secretaria de Educação Básica.

Braz, J. E. (2011) Longas cartas para ninguém. Ilustrações Salmo Dansa. Rio de Janeiro:

Rovelle.

Camargo, L. (1995) Ilustração do livro infantil. Belo Horizonte: Ed. Lê.

Farbiarz, J. L. (2006) Design na leitura: um dos percursos do Núcleo de Estudos do Design do Livro da PUC-Rio. Disponível em: http://www.dad.puc-rio.br/nel/artigos/06-farbiarz-livro.pdf. Acesso em: 09 agosto 2010.

Haslam, A. (2007) O livro e o designer II: Como criar e produzir livros. Tradução Juliana A. Saad e Sérgio Rossi Filho. São Paulo: Edições Rosari.

Gullar, F. (2013) Bichos do lixo. Ilustrações do autor. Rio de Janeiro: Casa da Palavra.

Gullar, F. (2012) Poemas escolhidos. Organização Walmir Ayala. 4.ed. revista. Rio de Janeiro: Ediouro Publicações de Passatempos e Multimídia.

Horn, A. (2013) Alô, mamãe!; Alô, papai!. Ilustrações Joelle Tourlonias. Tradução Heloisa Prieto. Curitiba: Editora Champagnat; PUC-PR.

Hunt, P. (2010) Crítica, teoria e literatura infantil. Tradução Cid Knipel. São Paulo: Cosac Naify.

Lacerda, M. G.; Farbiarz, J. L.; Oliveira, I. M. (2013) Design na leitura: uma possibilidade de mediação entre o jovem e a leitura literária. Dissertação (Mestrado). Rio de Janeiro: Pontifícia Universidade Católica do Rio de Janeiro.

Linden, S. V. (2011) Para ler o livro ilustrado. Tradução Dorothée de Bruchard. São Paulo: Cosac Naify.

Neto, L. (2018) FNDE vai limitar formatos para livros de literatura. Disponível em: http://www.publishnews.com.br/materias/2018/03/05/fnde-vai-limitar-formatos-para-livros-deliteratura Acesso em: 22 março 2018.

Neves, A. (2011) Maroca \& Deolindo e outros personagens em festas. Ilustrações do autor. São Paulo: Paulinas.

Neves, A. (2012) Tom. llustrações do autor. Porto Alegre: Editora Projeto.

Nikolajeva, M.; Scott, C. Livro ilustrado: palavras e imagens. Tradução Cid Knipel. São Paulo: Cosac Naify. American Institute of Graphic Arts. (n.d.). About AIGA. Disponível em https://www.aiga.org/about/

\section{Sobre as autoras}

Maíra Gonçalves Lacerda, Dra, UFF, Brasil <maira_lacerda@id.uff.br> Jackeline Lima Farbiarz, Dra, PUC-Rio, Brasil <jackeline@puc-rio.br> 